\title{
Investigation of the Validity and Reliability of a Placement Quality Survey for Measuring Rural Student Work Integrated Learning Placement Quality
}

\author{
*Sabrina Winona Pit ${ }^{a}$, Jo Longman ${ }^{b}$, Margaret Rolfe ${ }^{b}$, Lorraine Smith $^{b}$, \& Lindy McAllister ${ }^{b}$ \\ a: Western Sydney University, Australia; b: University of Sydney, Australia
}

\begin{abstract}
This study assessed the validity and reliability of the Placement Quality Survey (PQS) for measuring rural student clinical placement quality among allied health students attending rural placements. Secondly, the association of the PQS with students' choice of rural placements and rural self-efficacy was determined. Students attending 5-8-week placements completed a paper-based questionnaire and were also invited to complete it again later the same day for reliability testing. Reliability and validity were tested. Analysis of variance was used to investigate relationships between PQS items and composite scores with student discipline, venue of student placement, and rural self-efficacy. Occupational therapy, physiotherapy and speech pathology students $(N=163)$ participated. From the exploratory factor analysis a single factor was extracted which accounted for $62.1 \%$ of the variance. The standard one factor confirmatory factor analysis demonstrated reasonable fit but with the addition of a covariance term provided a good fit. Increased preference for rural placements was demonstrated for eight out of nine nine-item PQS items. Rural self-efficacy increased quality ratings, supporting construct validity. The Cronbach's alpha indicated a high level of internal consistency. All item-toitem correlations indicated a high level of consistency. Test-retest Pearson's correlations and intraclass correlation coefficients of repeatability indicated the reliability of the scale over time. This study validated the PQS in a sample of rural allied-health students. The results provided support for reliability. The study addresses the critical need for placement quality data to improve allied health students' experiences and learning outcomes on placements and encourage systematic quality improvement processes.
\end{abstract}

Keywords: health education; placements; placement quality measures; quality; validation studies

\section{Introduction}

Placement of students is a key element of medical and allied health student pre-registration courses, developing and refining clinical and work-ready skills (Davenport et al., 2018; Hills et al., 2019; McCall et al., 2009; van der Zwet et al., 2011) and is demanded by professional bodies (Australian Health Practitioner Regulation Agency, 2019). Students' choice of rural placements (Walters et al., 2016), their perception of their ability to practice rurally (Isaac et al., 2018) and well-supported rural clinical placements all promote students' intentions to practice rurally (Deaville \& Grant, 2011; King et al., 2016; Smith, Cross, et al., 2018; Smith, Sutton et al., 2018), and

*Corresponding Author: Sabrina Winona Pit, University Centre for Rural Health, School of Medicine,

Western Sydney University, University of Sydney, 62 Uralba Street, Lismore, New South Wales 2480, Australia.

Email: s.pit@westernsydney.edu.au

Journal URL: https://publications.coventry.ac.uk/index.php/pblh

Pit, S. W., Longman, J., Rolfe, M., Smith, L., \& McAllister, L. (2020). Investigation of the validity and reliability of a placement quality survey for measuring rural student work integrated learning placement quality. International Journal of Practice-based Learning in Health and Social Care, 8(2), 41-56. DOI 10.18552/ijpblhsc.v8i2.649. OpY NC ND ( 2020 Sabrina Winona Pit, Jo Longman, Margaret Rolfe, Lorraine Smith, \& Lindy McAllister. This
Open Access article is distributed under the terms of the Creative Commons Attribution Attribution-Non-Commercial No Derivatives 4.0 International License (https://creativecommons.org/licenses/by-nc-nd/4.0/ ), which permits unrestricted non-commercial use, distribution, and reproduction in any medium, provided the original work is properly cited and is unaltered. 
therefore play their part in addressing the urgent challenges of rural clinician recruitment and retention (Health Workforce Australia, 2011; Wakerman \& Humphreys, 2013; Wakerman \& Humphreys, 2019).

Measuring the quality of these student placements is integral to continuous quality improvement, providing an evidence-base to guide decisions about, for example, the most efficient and effective models of clinical education to invest in, preparing students prior to placement, and supervisor development programs. However, there have been few systematic efforts to assess quality of clinical placements (McAllister et al., 2010; McAllister et al., 2018; Nolte et al., 2011; Siggins Miller Consultants, 2012); rather, a range of factors related to quality has been identified (Cusick et al., 2014; Siggins Miller Consultants, 2012). For example, the Best Practice in Clinical Learning Environments (BPCLE) framework provides a model of practice for medicine, nursing and allied health clinical learning environments capturing features that support clinical placement experience (Darcy Associates, 2012). Cusick and colleagues conducted an international review of the clinical education and supervision literature, revealing a limited evidence base for innovation and evaluation in clinical education and no standardised measure for evaluation of clinical placement quality. They suggested that measures based on the BPCLE framework with the addition of measures of supervision might be an effective approach to developing quality measures (Cusick et al., 2014). To our knowledge, only one instrument which systematically and robustly measures quality in allied health has been developed and published (McAllister et al., 2018).

The Work Integrated Learning team at the University of Sydney set out to develop an instrument to measure placement quality in urban settings. They developed a suite of measures based on the BPCLE domains and added a question about the quality of supervision. The Placement Quality Survey (PQS) was developed for use by varoius stakeholders including external placement supervisors, worksite managers and clinical academics. This allows for student data to be triangulated with that of other stakeholders regarding quality of placements. Unlike other measures, this suite of measures is multidisciplinary and accounts for different stakeholder perspectives to allow for a more holistic set of quality outcomes to be measured from placements. This suite includes measures that allow for feedback from each stakeholder, thus maximising opportunities for quality improvement of the student learning experience (McAllister et al., 2018). McAllister and colleagues undertook a modified Delphi process, focus groups and surveys to develop a tool to measure placement quality and used exploratory factor analyses (EFA) to validate the tool. The authors found broad agreement on the elements that measure the quality of clinical placements amongst dentistry, medicine and pharmacy students. The tool was valid and reliable with EFA showing one component accounting for 58.5\% of the variance of survey data (McAllister et al., 2018).

There appears to be a lack of validated and reliable tools to assess the quality of placements for allied health students in rural settings. Therefore, this article builds on the survey developed by McAllister and colleagues (the PQS) by validating and testing the reliability of the survey for rural placements focussing on non-traditional community-based work-ready placements for allied health students (Longman et al., 2020). This may inform quality assurance and placement development in rural settings. Only the students' PQS was used at this point to reduce the burden of survey completion on time-poor rural clinical supervisors and worksite managers. Students' level of preference for rural placements (Walters et al., 2016) and their own perceptions of their ability to practice rurally (Isaac et al., 2018) were also investigated to validate the tool still further.

This study aimed to assess:

(1) the validity and reliability of the PQS for measuring rural student clinical placement quality among allied health students undertaking rural non-traditional community-based work-ready placements;

(2) the association of the PQS with students' preference for rural placements and rural self-efficacy.

\section{Methods}

\section{Study design and recruitment}

The study was a cross-sectional survey. Participants were occupational therapy, speech pathology and physiotherapy students from the University of Sydney undertaking a 5-8-week rural placement in New South Wales in non-traditional settings (schools, community health centres and aged care facilities). Recruitment involved a member of the research team approaching students face to face during the final week of their placement to explain the study, provide a participant information sheet, answer questions and invite participation (stressing the voluntary nature of participation). Completion of the paper-based questionnaire was taken to indicate consent to participation in the study. Recruitment took place between February and December 2018. The study was approved by the University of Sydney Human Research Ethics Committee (2015/466). 


\section{Data collection}

Students who completed the questionnaire (which took around ten minutes to complete) were also invited to answer seven questions again later on the same day for reliability testing. It was not possible to do the retesting two days later as the students were not available on campus. It was also not practical to conduct the survey in the last week before finishing their placements because $20 \%$ of their total placement time for those on five-week placements remained to be completed.

\section{Measures}

Placement Quality Survey (PQS): The initial seven-item survey consisted of seven main questions focussing on: the quality of the placement; the fit between placement site and supervision with the students' learning needs; quality of supervision; quality of the learning environment in the placement site; the level of communication between the university and placement site; the organisational culture of learning of the placement site; and finally, the level of teaching reflecting best practice (McAllister, 2016). Ratings scales ranged from 1, representing 'extremely poor', to 7, representing 'exceptional' scores.

Specific supervisory items: To enable continuous improvement of placements, two questions pertaining to the specific supervision model employed at the rural campus were added - autonomy and work readiness. Firstly, students were asked to rate "the extent to which you improved your ability to work autonomously due to the model of supervision you experienced during this placement". Secondly, students were asked to rate "the model of supervision on this placement in terms of increasing your work readiness" Both questions also required rating between 1 and 7. These two items were added to construct a nine-item survey to establish whether this would improve the validity of the PQS in a rural setting.

Student coordinators' support: Student coordination staff requested that the research team also ask the students to rate on a scale of 1-7 their satisfaction with "UCRH staff involvement and support before and during your placement". This item is not part of the seven- and nine-item PQS validation analyses but is reported for information purposes.

Rural factors: In addition, two additional questions focussed on rural factors: choice of rural placement (Walters et al., 2016) and rural self-efficacy (Isaac et al., 2018) were added. Choice of rural placement was measured on four levels with decreasing level of choice: "Yes, I chose to do a rural placement", "I was required to do a rural placement but was keen to do it anyway", "No, I didn't choose but I did not mind going", and "No, I didn't choose and I preferred not to go". Rural self-efficacy was measured by asking students to rate on a scale of 1-5 how much they agreed with the following statement: "I have a strong positive feeling when I think of working in a rural setting". This is the positive emotional arousal item of the rural self-efficacy scale (Isaac et al., 2015) and may approximate rural self-efficacy (Isaac et al., 2018).

\section{Statistical analyses}

Analyses were conducted using SAS ${ }^{\circ}$ 9.4. (https://support.sas.com/). Simple descriptive statistics were provided of student characteristics and the responses of the Clinical Placement Quality items (Table 1).

\section{Validity}

Firstly, an Exploratory Factor Analysis (EFA) was conducted to duplicate the methods used in the McAllister article (McAllister et al., 2018) to assess the degree to which the seven items in the PQS sufficiently explained the underlying construct of rural clinical placements. The Bartlett's Test of Sphericity (SAS Institute, 2020) was used to determine whether the data were suitable for factor analyses. The Kaiser-Meyer-Olkin Measure of Sampling Adequacy (Statistics How To, 2020) was used to determine sample adequacy, with a score above 0.60 being acceptable for sample adequacy. A single factor was extracted, with an Eigenvalue $>1$ indicating a single factor as being acceptable and the total variance of the items explaining the one-dimensional factor was calculated. The EFA component loadings were compared with the urban study. Following EFA, a Confirmatory Factor Analysis (CFA) was conducted to verify the single factor structure from the PQS constructed using an urban student sample. This allowed for testing the hypothesis that a relationship existed between the seven items and their underlying latent construct of clinical placement quality among rural students. The SAS CALIS Procedure was used to conduct a single factor CFA, which used the Weighted Least Squares (WLS) methodology to account for the categorical (and non-normal) nature of the 7 point response scale as recommended by Kline (2015). The standard maximum likelihood estimation method (ML) can result in a model chi-square being too high, resulting 
in rejecting true models (Kline, 2015). Modification indices were therefore used to indicate changes to improve model fit.

Individual items and composite scores were examined for their association with a number of salient predetermined outcome measures to measure construct validity. Our hypothesis was that students who preferred a rural placement would be more likely to assign higher scores for placement quality measures than other students. A chi-square test for linear trend was used to measure this for individual PQS items. Similarly, students with a higher score on rural self-efficacy were expected to assign higher scores to the individual and composite placement quality measures. One-way analysis of variance was conducted using the PQS seven-item composite measure with the rural self-efficacy score. Four levels of rural self-efficacy were used instead of five because the lowest two (1-2) levels were combined due to lack of numbers on the composite score for placement quality $(n=$ 157). Polynomial contrasts were fitted to assess the linearity of the response.

As it was perceived that the PQS supervision item may not have captured the quality of rural supervision models adequately, the factor analyses procedure was repeated adding the two new rural supervision-specific items to assess if adding these items yielded similar results (the nine-item PQS).

\section{Reliability}

Reliability was measured in two ways:

(1) Cronbach's Alpha and Pearson correlation coefficients were calculated to demonstrate internal consistency/scale reliability. This measured how well the items were related to each other as a group. Cronbach's alpha was compared with the urban study;

(2) Test-retest reliability was assessed by asking the students to complete the measure again several hours after completing it the first time and after a busy day of education. Bivariate correlation (Pearson's correlation) was conducted to assess the relative reliability of the seven-item and nine-item survey over time. A correlation coefficient of more than 0.7 needed to be achieved for each survey item paired over time. The Pearson's correlations were compared with the urban study. Additionally, intra-class correlation coefficients (ICC) scores were calculated for the seven-item and nine-item PQS with scores above 0.7 again suggesting relative reliability over time. The nine-item PQS included the two extra supervisory model questions.

\section{Sample size}

The PQS consisted of seven items. To allow for a sufficient sample size, we required a minimum of ten cases per survey item for the EFA (Hair et al., 1998) and ten cases per estimated parameter for the CFA (Kline, 2015). We therefore aimed to recruit 140 students. Test-retest reliability was conducted among the first 68 students due to time limitations.

\section{Results}

\section{Sample description and students' ratings}

A total of 163 students completed the survey, a response rate of $88 \%$. Table 1 shows that the majority of students studied physiotherapy (50.9\%), were in the second year of a Masters degree (59.5\%), and had strong positive feelings when thinking of working in a rural setting (62.5\%, scores of 4 and 5). The majority did not choose a rural placement but $36.6 \%$ did not mind going; however $15.5 \%$ preferred not to go.

Table 2 and Table 4 show that students' ratings and mean scores of the quality of the placement were generally high across all dimensions. The highest mean scores were found for staff involvement and support before and during students' placement (5.61) and students being able to work autonomously (5.57). The lowest mean score was found for organisational culture of learning at the site of students' clinical placement (4.27).

There was no significant difference between disciplines (Table 4) in relation to overall placement ratings and quality of placements for eight out of ten placement quality items $(p>0.05)$. There was a significant difference between disciplines in relation to work-readiness $(p=0.041$; item 5) and rural staff support $(p=0.005$, item 9). Neither item was not part of the seven-item PQS survey. 
Types of placements included schools, aged care and community health centres. There were significant differences between type of placements (Table 4) in relation to overall placement ratings and the way students rated the quality of their placements for five out of ten placement quality items $(p>0.05)$. Specifically, placements in schools rated lower on learning needs (ANOVA $p=0.048$ ), supervision (ANOVA $p=0.004$ ), learning environment (ANOVA $p=0.014$ ), rural staff support (ANOVA $p=0.022$ ) and clinical practice knowledge (ANOVA $p=0.015$ ).

Table 1: Students' characteristics, rural self-efficacy and rural placement control of choice 2018, $N=163$

\begin{tabular}{|c|c|c|}
\hline & $n$ & $\%$ \\
\hline \multicolumn{3}{|l|}{ Degree } \\
\hline Physio & 83 & 50.9 \\
\hline Occupational Therapy & 32 & 19.6 \\
\hline Speech & 48 & 29.4 \\
\hline \multicolumn{3}{|l|}{ Year } \\
\hline 2nd & 3 & 1.2 \\
\hline 3 rd & 38 & 23.3 \\
\hline 4th & 26 & 16.0 \\
\hline 1st Masters & 0 & 0.0 \\
\hline 2nd Masters & 97 & 59.5 \\
\hline \multicolumn{3}{|l|}{$\begin{array}{l}\text { I have a strong positive feeling when I think of working in a rural } \\
\text { setting (rural self-efficacy) }\end{array}$} \\
\hline Strongly disagree & 1 & 0.6 \\
\hline 2 & 13 & 8.1 \\
\hline 3 & 46 & 28.8 \\
\hline 4 & 63 & 39.4 \\
\hline Strongly agree & 37 & 23.1 \\
\hline \multicolumn{3}{|l|}{ Did you choose to do a rural placement? ${ }^{b}$} \\
\hline Yes I chose to do a rural placement & 42 & 26.1 \\
\hline I was required to do a rural placement but was keen to do it anyway & 35 & 21.7 \\
\hline No, I didn't choose but I did not mind going & 59 & 36.6 \\
\hline No, I didn't choose and I preferred not to go & 25 & 15.5 \\
\hline
\end{tabular}

${ }^{a}$ Missing $n=3 .{ }^{b}$ Missing $n=2$.

\section{Validity testing seven-item and nine-item PQS}

\section{Step 1: Exploratory Factor Analyses}

Seven-item: Exploratory Factor Analysis was conducted to assess the relative contribution of the PQS used in a rural setting and this confirmed the validity of the survey as one single component for measuring the quality of placements (Table 3). Bartlett's Test of Sphericity and Kaiser-Meyer-Olkin Measure of Sampling adequacy were satisfied. A single factor with eigenvalue greater than 1 was extracted accounting for $62.1 \%$ of the variance. The strongest two components were learning environment (loading of 0.85 ) followed by learning needs (loading of 0.84 ), where all other items head loading ranging from 0.74 to 0.79 . These loadings were very similar to the urban placement EFA (see Table 3).

Nine-item: The additional item of 'work ready' was consistent with the loading range of the seven-item scale (0.70) but 'autonomous' demonstrated a somewhat lower loading (0.66). In order to compare the relative contribution of the nine-item instrument compared to the seven-item PQS, in a similar manner, a single factor was accounting for $57.8 \%$ of the variance compared to $62.1 \%$ for the original seven-item tool. 
Table 2: Students' ratings of the quality of the placement, 2018, $N=163$

\begin{tabular}{|c|c|c|c|c|c|c|c|}
\hline Overall, how would you rate: & $\begin{array}{l}\text { Extremely } \\
\text { poor }\end{array}$ & 2 & 3 & 4 & 5 & 6 & Exceptional \\
\hline & $\%$ & $\%$ & $\%$ & $\%$ & $\%$ & $\%$ & $\%$ \\
\hline - the quality of this placement & 0.0 & 1.0 & 5.5 & 12.9 & 41.1 & 30.7 & 9.2 \\
\hline $\begin{array}{l}\text { - the fit between the placement site and } \\
\text { supervision you received and your learning } \\
\text { needs? (miss }=1 \text { ) }\end{array}$ & 0.0 & 3.7 & 8.0 & 16.0 & 34.0 & 25.9 & 12.3 \\
\hline - the quality of supervision you received & 0.0 & 2.5 & 9.2 & 10.4 & 27.0 & 32.5 & 18.4 \\
\hline $\begin{array}{l}\text { - the quality of the learning environment in the } \\
\text { workplace? }\end{array}$ & 0.0 & 3.0 & 6.7 & 17.2 & 35.6 & 28.8 & 9.8 \\
\hline $\begin{array}{l}\text { - the level of communication between the UCRH } \\
\text { and the site of your clinical placement? }\end{array}$ & 0.6 & 2.5 & 6.1 & 17.8 & 30.1 & 28.2 & 14.7 \\
\hline $\begin{array}{l}\text { - the organisational culture of learning at the site } \\
\text { of your clinical placement? (miss }=2)\end{array}$ & 1.9 & 3.1 & 10.6 & 14.9 & 32.3 & 27.3 & 9.9 \\
\hline $\begin{array}{l}\text { the extent to which you improved your ability to } \\
\text { work autonomously due to the model of } \\
\text { supervision you experienced during this } \\
\text { placement }\end{array}$ & 0.0 & 0.6 & 3.7 & 7.4 & 26.4 & 40.5 & 21.5 \\
\hline $\begin{array}{l}\text { - the model of supervision on this placement in } \\
\text { terms of increasing your work readiness? }\end{array}$ & 0.0 & 1.8 & 1.8 & 13.5 & 28.8 & 40.5 & 14.1 \\
\hline $\begin{array}{l}\text { - UCRH staff involvement and support before } \\
\text { and during your placement? (miss=1) }\end{array}$ & 0.0 & 0.6 & 3.7 & 11.7 & 24.1 & 32.7 & 27.2 \\
\hline $\begin{array}{l}\text { Based on your knowledge, was the suite of } \\
\text { practice skills and clinical reasoning you were } \\
\text { taught best practice clinical practice and } \\
\text { knowledge? }\end{array}$ & 1.2 & 1.2 & 5.5 & 12.9 & 27.6 & 38.7 & 12.9 \\
\hline
\end{tabular}

Table 3: Component Matrix for the single component of the 7-item and 9-item PQS from Exploratory Factor Analysis $(2018, n=160)$ compared to urban placements ${ }^{\mathrm{a}}$

\begin{tabular}{|l|r|r|r|}
\hline Overall, how would you rate: & $\begin{array}{l}\text { Rural } \\
\text { 7-item }\end{array}$ & $\begin{array}{l}\text { Rural } \\
9-\text { item }\end{array}$ & $\begin{array}{l}\text { Urban } \\
7-\text { item }\end{array}$ \\
\hline$\bullet \quad$ the quality of this placement? & 0.74 & 0.76 & 0.79 \\
\hline - $\quad \begin{array}{l}\text { the fit between the placement site and supervision you received and your } \\
\text { learning needs? }\end{array}$ & 0.84 & 0.83 & 0.81 \\
\hline - $\quad$ the quality of supervision you received? & 0.78 & 0.76 & 0.79 \\
\hline - $\quad$ the quality of the learning environment in the workplace? & 0.85 & 0.85 & 0.83 \\
\hline - $\quad \begin{array}{l}\text { the level of communication between the UCRH and the site of your clinical } \\
\text { placement? }\end{array}$ & 0.77 & 0.75 & 0.67 \\
\hline - $\quad$ the organisational culture of learning at the site of your clinical placement? & 0.79 & 0.76 & 0.74 \\
\hline - $\quad \begin{array}{l}\text { based on your knowledge, was the suite of practice skills and clinical } \\
\text { reasoning you were taught best practice clinical practice and knowledge? }\end{array}$ & 0.74 & 0.71 & 0.72 \\
\hline $\begin{array}{l}\text { the extent to which you improved your ability to work autonomously due to } \\
\text { the model of supervision you experienced during this placement? }\end{array}$ & & 0.66 & \\
\hline $\begin{array}{l}\text { the model of supervision on this placement in terms of increasing your work } \\
\text { readiness? }\end{array}$ & & 0.76 & \\
\hline
\end{tabular}

${ }^{\mathrm{a}}$ McAllister et al., 2018 
Table 4: Students' ratings of the quality of the placement overall and the associations between discipline, site type and students' mean ratings of the quality of the placement $(2018, n=160)$.

\begin{tabular}{|c|c|c|c|c|c|c|c|c|c|c|c|c|c|c|c|}
\hline \multirow[t]{2}{*}{ Overall, how would you rate: } & \multirow[b]{2}{*}{$\begin{array}{l}\text { Item } \\
\text { no }\end{array}$} & \multirow[b]{2}{*}{ Mean } & \multirow[b]{2}{*}{$S D^{1}$} & \multirow[b]{2}{*}{$\begin{array}{l}S E \text { of } \\
\text { mean }\end{array}$} & \multirow[b]{2}{*}{$\mathrm{Q} 1^{2}$} & \multirow[b]{2}{*}{ Median } & \multirow[b]{2}{*}{$\mathrm{Q}^{3}$} & \multicolumn{4}{|c|}{ Discipline } & \multicolumn{4}{|l|}{ Site type } \\
\hline & & & & & & & & $\begin{array}{l}\text { PT } \\
n=82\end{array}$ & $\begin{array}{l}\text { OT } \\
n=32\end{array}$ & $\begin{array}{l}\text { Speech } \\
n=46\end{array}$ & $\begin{array}{l}p- \\
\text { value }^{4}\end{array}$ & $\begin{array}{l}\text { Aged } \\
\text { care } \\
n=80\end{array}$ & $\begin{array}{l}\text { Schools } \\
n=26\end{array}$ & $\begin{array}{l}\text { Community } \\
\text { Health } \\
n=10\end{array}$ & $p$-value ${ }^{4}$ \\
\hline - the quality of this placement & 1 & 5.22 & 1.02 & .081 & 5.0 & 5.0 & 6.0 & 5.26 & 5.38 & 5.04 & 0.332 & 5.18 & 5.15 & 5.00 & 0.881 \\
\hline $\begin{array}{l}\text { - the fit between the placement site and } \\
\text { supervision you received and your } \\
\text { learning needs? }\end{array}$ & 2 & 5.06 & 1.25 & .099 & 4.0 & 5.0 & 6.0 & 5.09 & 5.22 & 4.89 & 0.503 & 5.10 & 4.42 & 5.00 & 0.048 \\
\hline $\begin{array}{l}\text { - the quality of supervision you } \\
\text { received }\end{array}$ & 3 & 5.32 & 1.30 & .102 & 5.0 & 5.5 & 6.0 & 5.29 & 5.38 & 5.33 & 0.954 & 5.40 & 4.54 & 5.80 & 0.004 \\
\hline $\begin{array}{l}\text { - the quality of the learning } \\
\text { environment in the workplace? }\end{array}$ & 6 & 5.10 & 1.13 & .089 & 4.0 & 5.0 & 6.0 & 5.00 & 4.94 & 5.39 & 0.112 & 4.99 & 4.81 & 6.00 & 0.014 \\
\hline $\begin{array}{l}\text { the level of communication between } \\
\text { the UCRH and the site of your clinical } \\
\text { placement? }\end{array}$ & 7 & 5.19 & 1.24 & .098 & 4.0 & 5.0 & 6.0 & 5.27 & 4.91 & 5.23 & 0.346 & 5.17 & 4.69 & 5.40 & 0.192 \\
\hline $\begin{array}{l}\text { the organisational culture of } \\
\text { learning at the site of your clinical } \\
\text { placement? }\end{array}$ & 8 & 4.94 & 1.36 & .107 & 4.0 & 5.0 & 6.0 & 4.91 & 4.66 & 5.20 & 0.217 & 4.80 & 4.62 & 5.60 & 0.174 \\
\hline $\begin{array}{l}\text { - the extent to which you improved } \\
\text { your ability to work autonomously due } \\
\text { to the model of supervision you } \\
\text { experienced during this placement }\end{array}$ & 4 & 5.66 & 1.05 & .083 & 5.0 & 6.0 & 6.0 & 5.62 & 5.66 & 5.72 & 0.886 & 5.63 & 5.81 & 6.00 & 0.492 \\
\hline $\begin{array}{l}\text { - the model of supervision on this } \\
\text { placement in terms of increasing your } \\
\text { work readiness? }\end{array}$ & 5 & 5.44 & 1.07 & .084 & 5.0 & 6.0 & 6.0 & 5.24 & 5.75 & 5.59 & 0.041 & 5.28 & 5.54 & 5.90 & 0.189 \\
\hline $\begin{array}{l}\text { UCRH staff involvement and } \\
\text { support before and during your } \\
\text { placement? }\end{array}$ & 9 & 5.67 & 1.13 & .090 & 5.0 & 6.0 & 7.0 & 5.95 & 5.39 & 5.37 & 0.005 & 5.85 & 5.16 & 5.40 & 0.022 \\
\hline $\begin{array}{l}\text { Based on your knowledge, was the } \\
\text { suite of practice skills and clinical } \\
\text { reasoning you were taught best practice } \\
\text { clinical practice and knowledge? }\end{array}$ & 10 & 5.30 & 1.21 & .096 & 5.0 & 6.0 & 6.0 & 5.30 & 5.03 & 5.48 & 0.278 & 5.26 & 4.62 & 5.90 & 0.015 \\
\hline PQS Total Score 7 item $^{5}$ & - & 36.13 & 6.70 & 0.53 & 32.0 & 37.0 & 40.0 & - & - & - & - & - & - & - & - \\
\hline PQS Total Score 9 item $^{6}$ & - & 47.23 & 8.07 & 0.638 & 42.3 & 48.0 & 52.8 & - & - & - & - & - & - & - & \\
\hline
\end{tabular}

${ }^{1}$ Standard deviation. ${ }^{2} 25$ th percentile. ${ }^{3} 75$ th percentile. ${ }^{4}$ ANOVA. ${ }^{5}$ PQS total score 7 item based on: item numbers: $1+2+3+6+7+8+10 .{ }^{6} \mathrm{PQS}$ total score 9 item based on: item numbers: $1+2+3+6+7+8+10+4+5$ 


\section{Step 2: Confirmatory Factor Analysis}

Seven-item: Two CFA models were fitted (Table 5) where Model 1 was the usual one-factor CFA and Model 2 was Model 1 with an additional covariance between Fit and Supervision due to the higher correlation between the two variables (0.777) (see Appendix A - Table A.1). The model fit was significantly improved with the addition of the covariance parameter with all measures of fit such as chisquare difference $=11.21$ on $1 d f p<0.001$; the model chi-square statistic became non-significant $(p=$ 0.062 ); the SRMR of 0.058 was less than 0.10 which indicated a good fit; the RMSEA (Root Mean Square Error of Approximation) reduced to below 0.08 which suggested reasonable approximation of fit (where $<=0.05$ indicates close fit); a lower RMSEA $90 \%$ bound of 0 indicated a better fit although an upper $90 \%$ bound $>0.10$ does not. In summary, the standard one factor CFA demonstrated reasonable fit but with the addition of a covariance term provided an improved fit on most goodness-of-fit measures.

Table 5: Results of Single construct Confirmatory Factor Analysis modelling - seven-item

\begin{tabular}{|c|c|c|c|c|c|c|c|}
\hline & & Model 1 & & & Model 2 & & \\
\hline Parameter & & $\begin{array}{l}\text { Unstand- } \\
\text { ardized }\end{array}$ & $S E$ & $\begin{array}{l}\text { Standard } \\
\text {-ized }\end{array}$ & $\begin{array}{l}\text { Unstand- } \\
\text { ardized }\end{array}$ & SE & $\begin{array}{l}\text { Standard } \\
\text {-ized }\end{array}$ \\
\hline \multicolumn{8}{|l|}{ Loadings from F1 } \\
\hline Quality & $\lambda 1$ & 0.659 & 0.092 & 0.681 & 0.712 & 0.083 & 0.713 \\
\hline Fit & $\lambda 2$ & 1.007 & 0.083 & 0.886 & 1.000 & & 0.814 \\
\hline Supervision & $\lambda 3$ & 0.959 & 0.098 & 0.821 & 0.906 & 0.057 & 0.725 \\
\hline Learning Environment & $\lambda 4$ & 0.890 & 0.063 & 0.848 & 0.947 & 0.072 & 0.858 \\
\hline Communication & $\lambda 5$ & 0.855 & 0.073 & 0.802 & 0.904 & 0.089 & 0.788 \\
\hline Organisational Culture & $\lambda 6$ & 1.000 & & 0.791 & 1.037 & 0.086 & 0.794 \\
\hline Best Practice & $\lambda 7$ & 0.774 & 0.079 & 0.681 & 0.855 & 0.078 & 0.695 \\
\hline \multicolumn{8}{|l|}{ Variances/Co-variances } \\
\hline Latent variable F1 & Phi1 & 1.109 & 0.174 & & 1.021 & 0.149 & \\
\hline Quality & Var 1 & 0.556 & 0.071 & & 0.501 & 0.075 & \\
\hline Fit & Var 2 & 0.309 & 0.050 & & 0.520 & 0.078 & \\
\hline Supervision & Var 3 & 0.492 & 0.074 & & 0.756 & 0.105 & \\
\hline Learning Environment & Var 4 & 0.343 & 0.045 & & 0.328 & 0.047 & \\
\hline Communication & Var 5 & 0.449 & 0.069 & & 0.517 & 0.073 & \\
\hline Organisational Culture & Var 6 & 0.664 & 0.107 & & 0.642 & 0.107 & \\
\hline Best Practice & Var 7 & 0.766 & 0.111 & & 0.800 & 0.111 & \\
\hline \multirow[t]{2}{*}{ Covar Fit $\leftrightarrow$ Supervision } & $\operatorname{Cov} 23$ & & & & 0.275 & 0.080 & \\
\hline & & Model 1 & & & Model 2 & & \\
\hline \multicolumn{8}{|l|}{ Measures of fit } \\
\hline Model chi-square & & 32.78 & & & 21.57 & & \\
\hline Model chi-square $d f$ & & 14 & & & 13 & & \\
\hline Probability Model chi-square & & 0.003 & & & 0.062 & & \\
\hline Model chi-square/ $d f$ ratio & & 2.34 & & & 1.66 & & \\
\hline$R M R$ & & 0.124 & & & 0.091 & & \\
\hline SRMR & & 0.078 & & & 0.058 & & \\
\hline GFI & & 0.922 & & & 0.948 & & \\
\hline Adjust $G F I$ & & 0.843 & & & 0.889 & & \\
\hline RMSEA $(90 \% \mathrm{CI})$ & & $\begin{array}{l}0.092 \\
(0.051- \\
0.133)\end{array}$ & & & $\begin{array}{l}0.064(0- \\
0.111)\end{array}$ & & \\
\hline$A I C$ & & 60.78 & & & 51.57 & & \\
\hline Bentler CFI & & 0.852 & & & 0.932 & & \\
\hline
\end{tabular}

Key: $d f$ - degrees of freedom; $R M R$ - root mean square residual; SRMR - Standardized Root Mean Square Residual; GFI - Goodness of fit; RMSEA - Root Mean Square Error of Approximation; AIC Akaike information criterion.

Nine-item: The CFA analyses is presented in Appendix A Table A.2. Three CFA models were fitted where Model 1 was the usual 1 factor CFA and Model 2 was Model 1 with an additional covariance 
between Fit and Supervision due to the higher correlation (0.777) and Model 3 with an additional covariance between the two additional items of Autonomous and Work Ready. The model fit was significantly improved with the addition of each of the covariance parameters with all measures of fit. Model 3 indicated the best fit over a range of measures. Thus the nine item one factor CFA demonstrated a good fit with the addition of two covariance terms (Appendix A Table A.3a and Table A.3b).

Table 6: Associations between choice of placement and students' ratings of the quality of the placement and rural self-efficacy: mean ratings $(2018, n=160)$

\begin{tabular}{|c|c|c|c|c|c|}
\hline Overall, how would you rate: & $\begin{array}{l}\text { Yes, I } \\
\text { chose to } \\
\text { do a rural } \\
\text { placement }\end{array}$ & $\begin{array}{l}\text { I was } \\
\text { required } \\
\text { to do a } \\
\text { rural } \\
\text { placement } \\
\text { but was } \\
\text { keen to } \\
\text { do it } \\
\text { anyway }\end{array}$ & $\begin{array}{l}\text { No, I } \\
\text { didn't } \\
\text { choose but } \\
\text { I did not } \\
\text { mind } \\
\text { going }\end{array}$ & $\begin{array}{l}\text { No, I didn't } \\
\text { choose and } \\
\text { I preferred } \\
\text { not to go }\end{array}$ & $\begin{array}{l}p \text {-value } \\
\text { for } \\
\text { linear } \\
\text { trend }\end{array}$ \\
\hline & $n=42$ & $n=33$ & $n=59 / 58$ & $n=24$ & \\
\hline - the quality of this placement? & 5.67 & 5.30 & 5.15 & 4.50 & $<0.001$ \\
\hline $\begin{array}{l}\text { the fit between the placement } \\
\text { site and supervision you } \\
\text { received and your learning } \\
\text { needs? }\end{array}$ & 5.64 & 5.18 & 4.86 & 4.29 & $<0.001$ \\
\hline $\begin{array}{l}\text { the quality of supervision you } \\
\text { received? }\end{array}$ & 5.79 & 5.36 & 5.15 & 4.92 & 0.007 \\
\hline $\begin{array}{l}\text { - the quality of the learning } \\
\text { environment in the } \\
\text { workplace? }\end{array}$ & 5.55 & 5.12 & 4.90 & 4.71 & 0.003 \\
\hline $\begin{array}{l}\text { - the level of communication } \\
\text { between the UCRH and the site } \\
\text { of your clinical placement? }\end{array}$ & 5.55 & 5.46 & 4.98 & 4.75 & 0.005 \\
\hline $\begin{array}{l}\text { the organisational culture of } \\
\text { learning at the site of your } \\
\text { clinical placement? }\end{array}$ & 5.43 & 4.97 & 4.76 & 4.54 & 0.008 \\
\hline $\begin{array}{l}\text { Based on your knowledge, was } \\
\text { the suite of practice skills and } \\
\text { clinical reasoning you were } \\
\text { taught best practice clinical } \\
\text { practice and knowledge? }\end{array}$ & 5.67 & 5.36 & 5.05 & 5.17 & 0.062 \\
\hline $\begin{array}{l}\text { the extent to which you } \\
\text { improved your ability to work } \\
\text { autonomously due to the } \\
\text { model of supervision you } \\
\text { experienced during this } \\
\text { placement? }\end{array}$ & 6.07 & 5.76 & 5.51 & 5.17 & $<0.001$ \\
\hline $\begin{array}{l}\text { the model of supervision on } \\
\text { this placement in terms of } \\
\text { increasing your work } \\
\text { readiness? }\end{array}$ & 5.81 & 5.42 & 5.31 & 5.17 & 0.017 \\
\hline $\begin{array}{l}\text { - UCRH staff involvement and } \\
\text { support before and during } \\
\text { your placement? }(n=158)\end{array}$ & 6.14 & 5.88 & 5.48 & 5.04 & $<0.001$ \\
\hline $\begin{array}{l}\text { I have a strong positive feeling } \\
\text { when I think of working in a } \\
\text { rural setting (rating: } 1-5) \\
\text { (rural self-efficacy) }(n=158)\end{array}$ & 4.19 & 3.97 & 3.59 & 3.17 & $<0.001$ \\
\hline
\end{tabular}




\section{Step 3: Construct validity}

\section{Choice of rural placement}

Table 6 demonstrates that for all but one item a significant difference existed between students' ability to control their choice of rural placement and their ratings of the quality of their placements. The more control a student had, the higher their ratings were. This is displayed through a statistically significant linear trend from analysis of variance analyses for all items except for best clinical practice, although this almost reached statistical significance $(p=0.062)$. Choosing a rural placement always resulted in a significantly higher rating ( $\mathrm{p}$ ranged from $p<0.001$ to $p=0.024$ ) than preferring not to go for all quality attributes except for best clinical practice $(p=0.126)$ using specified contrasts.

Our hypothesis was confirmed that students who preferred a rural placement would be more likely to score higher on placement quality measures than other students. Table 6 also shows that the higher a student's preference was to go on a rural placement, the higher their rural self-efficacy score was.

Rural self-efficacy: Table 7 shows that in the ANOVA for both the seven- and nine-item PQS composite, the rural self-efficacy factor was significant $\left(F_{3,153}=13.796, p<0.001\right.$ and $F_{3,153}=13.533, p<0.001$ respectively) with a significant linear component $p<0.001$ for both. Thus, students who scored higher on rural self-efficacy also had higher placement quality scores on both the seven- and nine-item PQS. Our hypothesis was confirmed, that students with a higher score on rural self-efficacy scored higher on the individual and composite placement quality measures.

Table 7: Rural self-efficacy ("I have a strong positive feeling when I think of working in a rural setting (rating: 1-5)" estimated marginal means, $S E$ and $95 \%$ CI for placement quality survey

\begin{tabular}{|l|l|l|l|l|l|l|}
\hline & \multicolumn{4}{|l|}{ 7-item PQS } & \multicolumn{3}{l|}{ 9-item PQS } \\
\hline Rural self-efficacy level & Mean & $S E$ & $95 \%$ CI & Mean & SE & $95 \%$ CI \\
\hline $1-2$ & 4.388 & 0.228 & $3.937-4.838$ & 4.508 & 0.214 & $4.084-4.932$ \\
\hline 3 & 4.719 & 0.127 & $4.468-4.970$ & 4.843 & 0.120 & $4.607-5.080$ \\
\hline 4 & 5.379 & 0.109 & $5.164-5.595$ & 5.452 & 0.103 & $5.249-5.655$ \\
\hline 5 & 5.683 & 0.140 & $5.406-5.961$ & 5.730 & 0.132 & $5.469-5.990$ \\
\hline
\end{tabular}

\section{Reliability testing}

Step 1: Internal consistency

Seven-item: Internal consistency or scale reliability was assessed for the seven items of the PQS (Table 8). The Cronbach's alpha was 0.896 , which indicated a high level of consistency $(>0.70)$ and was maximised with the inclusion of all seven items. Our Cronbach's alpha was very similar to the urban study (0.87) (McAllister et al., 2018). This suggests a robust structure. The Pearson correlations for the upper diagonal item-to-item correlation matrix between the seven items and the item-to-total correlations are presented in Table 8. All item-to-item correlations were greater than 0.3 with a range of 0.419 to 0.777 and item-to-total correlations greater than 0.5 , ranging from 0.640 to 0.784 , all of which endorsed a high level of consistency.

Table 8: Item-to-Item Pearson's correlations and Item-to-Total correlations for the 7 items of the PQS $(n=160)$

\begin{tabular}{|c|c|c|c|c|c|c|c|c|}
\hline & Fit & Supervision & Learning & Communication & Culture & $\begin{array}{l}\text { Best } \\
\text { Practice }\end{array}$ & $\begin{array}{l}\text { 7-item- } \\
\text { Total }\end{array}$ & $\begin{array}{l}\text { 9-item- } \\
\text { Total }\end{array}$ \\
\hline Quality & 0.592 & 0.466 & 0.599 & 0.537 & 0.477 & 0.420 & 0.640 & \\
\hline Fit & & 0.777 & 0.629 & 0.505 & 0.532 & 0.557 & 0.763 & \\
\hline Supervision & & & 0.602 & 0.419 & 0.469 & 0.563 & 0.683 & \\
\hline $\begin{array}{l}\text { Learning } \\
\text { Environment }\end{array}$ & & & & 0.628 & 0.657 & 0.562 & 0.784 & \\
\hline $\begin{array}{l}\text { Communica- } \\
\text { tion }\end{array}$ & & & & & 0.629 & 0.492 & 0.685 & \\
\hline Culture & & & & & & 0.531 & 0.705 & \\
\hline Best Practice & & & & & & & 0.646 & \\
\hline Autonomy & & & & & & & & 0.562 \\
\hline Work ready & & & & & & & & 0.686 \\
\hline
\end{tabular}


Nine-item: The Cronbach's alpha was 0.907 , which indicated a high level of consistency $(>0.70)$ and was maximised with the inclusion of all 9 items. This Cronbach's alpha score was higher than the seven-item PQS (0.896).

The Pearson correlations for the item-to-item correlation of the additional two items with the original seven items are presented in Appendix A, Table A.2, and the Pearson correlations with the item-to-total correlations are presented in Table 8. The additional items had all item-to-item correlations greater than 0.3; however, the item Autonomous had lower correlations with some of the original items $(0.320-0.531)$ than any of the seven item-to-item correlations (minimum 0.419 between supervision and communication [Table 8]). All item-to-total correlations were greater than 0.5 and, again, Autonomous was the lowest.

\section{Step 2 Test-retest reliability}

Bivariate correlation (Pearson's correlation) was conducted to assess the relative reliability of the sevenitem and nine-item PQS over time (Table 9). All seven items of the survey and the nine-item construct coefficients scored above 0.7 , indicating the reliability of the scale over time. ICC scores for the sevenitem and nine-item construct were also all above 0.7 suggesting again relative reliability overtime.

Table 9: Test-retest correlations for the Placement Quality Survey $(n=160)$, staff support and rural self-efficacy and choice compared to urban placements ${ }^{\mathrm{a}}$

\begin{tabular}{|c|c|c|c|c|c|c|c|c|c|c|c|}
\hline & \multicolumn{3}{|c|}{ Rural } & \multicolumn{2}{|l|}{ Urban $^{\mathrm{a}}$} & \multicolumn{6}{|c|}{ Intraclass Correlation } \\
\hline & $n$ & $\begin{array}{l}\text { Pearson } \\
\text { correl- } \\
\text { ation }\end{array}$ & $p$-value & $\begin{array}{l}\text { Pearson } \\
\text { correl- } \\
\text { ation }\end{array}$ & $p$-value & ICC & $\begin{array}{l}95 \% \\
\text { CI } \\
\text { Lower } \\
\text { bound }\end{array}$ & $\begin{array}{l}95 \% \\
\text { CI } \\
\text { Upper } \\
\text { bound }\end{array}$ & $F$-test & $\mathrm{df}$ & $p$-value \\
\hline Quality & 66 & 0.866 & $<0.001$ & 0.85 & $<0.001$ & 0.861 & 0.783 & 0.912 & 13.374 & 65 & $<0.001$ \\
\hline Fit & 66 & 0.884 & $<0.001$ & 0.85 & $<0.001$ & 0.884 & 0.818 & 0.927 & 16.257 & 65 & $<0.001$ \\
\hline Supervision & 66 & 0.826 & $<0.001$ & 0.58 & $<0.001$ & 0.828 & 0.734 & 0.891 & 10.633 & 65 & $<0.001$ \\
\hline $\begin{array}{l}\text { Learning } \\
\text { Environment }\end{array}$ & 66 & 0.721 & $<0.001$ & 0.74 & $<0.001$ & 0.713 & 0.572 & 0.814 & 5.979 & 65 & $<0.001$ \\
\hline Communication & 66 & 0.851 & $<0.001$ & 0.69 & $<0.001$ & 0.851 & 0.768 & 0.906 & 12.445 & 65 & $<0.001$ \\
\hline Culture & 65 & 0.768 & $<0.001$ & 0.55 & 0.003 & 0.767 & 0.645 & 0.851 & 7.583 & 64 & $<0.001$ \\
\hline Best Practice & 65 & $0.799^{*}$ & $<0.001$ & 0.54 & 0.004 & 0.794 & 0.684 & 0.869 & 8.716 & 64 & $<0.001$ \\
\hline Autonomy & 66 & 0.861 & $<0.001$ & & & 0.857 & 0.776 & 0.910 & 12.944 & 65 & $<0.001$ \\
\hline Work readiness & 66 & 0.773 & $<0.001$ & & & 0.765 & 0.644 & 0.849 & 7.516 & 65 & $<0.001$ \\
\hline Staff support & 65 & 0.671 & $<0.001$ & & & 0.664 & 0.503 & 0.780 & 4.951 & 64 & $<0.001$ \\
\hline Rural efficacy & 63 & 0.839 & $<0.001$ & & & - & - & - & - & - & $<0.001$ \\
\hline Rural Choice & 63 & 0.993 & $<0.001$ & & & - & - & - & - & - & $<0.001$ \\
\hline
\end{tabular}

${ }^{\text {a }}$ McAllister et al., 2018

\section{Discussion}

Exploratory and confirmatory factor analysis was conducted to assess the relative contribution of the PQS used in a rural setting and confirmed the validity of the PQS as one single component for measuring the quality of placements. Our EFA, test-retest and Cronbach's alpha findings were similar to those reported by McAllister et al. (2018) who validated the survey among students on urban placements. The decision was made to conduct an EFA in the rural sample because of the difference in rural and urban placements. Additionally, our study had a response rate of $88 \%$ compared to the urban study rate of $27 \%$, suggesting that the low response rate may have led to different factor loadings. However, it was encouraging to see that the results were very similar, indicating that the survey is potentially a robust tool. Increased preference for rural placements and rural self-efficacy increased quality ratings, supporting construct validity. Construct validity was established by correlating the PQS with choice of placement and rural self-efficacy. We can argue from the pattern of correlations that the PQS is associated with both variables in theoretically predictable ways. Additionally, reliability in terms of both internal consistency and repeatability was also satisfactory.

The addition of the two supervisory items was considered useful in the rural setting as part of quality assurance techniques for the rural campus to continue to inform improvement of the quality of rural placements. Although 'autonomy' during rural placements scored slightly lower than the other quality 
placement items, the results were valid and reliable, supporting inclusion of the item, as it gives extra information about the quality of the placement. Work-readiness and enhancing students' capacity to work autonomously are increasingly required skills for entering the workforce by industry (Winterton \& Turner, 2019). Therefore these two items could be used as measures of work-readiness and autonomy by clinical education teams. A recent study (Winterton \& Turner, 2019) critically evaluating existing opinions about graduates and work-readiness concluded that current education is poorly aligned with labour market needs. The study highlighted the need to find consensus between different stakeholder perspectives on graduate workforce readiness and make sure that stakeholders collaborate to improve graduate transition to the labour market, but noted this must be context-specific. The PQS may assist in this area by improving placement quality.

A robust linear trend was also clearly visible when students reported strong positive feelings when thinking of working in a rural setting leading to higher quality ratings, which in turn may promote students' intentions to practice rurally (Isaac et al., 2018; King et al., 2016).

Whilst not surprising, the results also confirm that students who had more choice about rural placement preference scored higher on their quality ratings. This is important because we know that a better experience is linked to intention to practising rurally in the future (Smith, Sutton et al., 2018; Walters et al., 2016). Rural clinical schools can use this information to measure both the quality of clinical placements and the intention to practice rurally, so they can check whether placement quality is linked to intention to practice rurally in their own clinical schools. Some would argue that only allocating students to rural placements that want to do a rural placement could be a potential selection criterion for allied health students to attend rural training. However, this raises the possibility that students who did not consider doing a rural placement may miss out on learning about the option of working in rural areas. Additionally, because our placements were short placements (4-8 weeks). This may not hold for longerterm placements.

\section{Limitations}

Rural self-efficacy was evaluated by including only one question of the rural self-efficacy scale (Isaac et al., 2015; Isaac et al., 2018), which has not been validated as a stand-alone item, but our survey needed to be brief.

The study was conducted among a group of allied health students from one rural area and self-reporting may have biased the results. The short time-frame to conduct the test-retest results may also have impacted the study results.

The two additional items relate specifically to the non-traditional model of supervision for these particular community-based work-ready placements (aimed at improving work-readiness and increasing students' skills and capacity to work autonomously) and may therefore not be applicable to more traditional placements. However, it may be time to begin conversations about making all students work-ready and autonomous.

\section{Conclusion}

This study enhanced measures of quality in clinical placements and validated an existing placement quality survey in a sample of rural allied health students. The results provided support for the reliability (both for internal consistency and repeatability), construct and factorial validity of the PQS. The study addresses the critical need for placement quality data to improve allied health students' experiences and learning outcomes on placements and the use of systematic quality-improvement processes in placements.

\section{Acknowledgements}

The authors would like to express their thanks to all rural allied health students who participated in the study and the staff who assisted with data collection.

\section{Ethical approval}

University of Sydney Human Research Ethics Committee (2015/466). 


\section{ORCID}

Sabrina Winona Pit https://orcid.org/0000-0003-2410-0703

Jo Longman https://orcid.org/0000-0002-8257-7772

Margaret Rolfe https://orcid.org/0000-0003-3041-1858

Lorraine Smith https://orcid.org/0000-0002-3499-1514

Lindy McAllister https://orcid.org/0000-0001-8715-3971

\section{References}

Australian Health Practitioner Regulation Agency. (2019). Fact sheet for education providers. https://www.ahpra.gov.au/Registration/Student-Registrations/fact-sheet-for-educationproviders.aspx

Cusick, A., Heydon, M., Caldwell, K., \& Cohen, L. (2014). Finding measures of clinical placements quality for pre-service health services training: Challenges of definition and search strategy construction. BMC Health Services Research, 14, P24. https://doi.org/10.1186/1472-6963-14$\underline{\mathrm{S} 2-\mathrm{P} 24}$

Darcy Associates. (2012). Best practice clinical learning environments: Final Report. Retrieved November, 2019 from http://www.health.vic.gov.au/placements/resources/index.htm

Davenport, R., Hewat, S., Ferguson, A., McAllister, S., \& Lincoln, M. (2018). Struggle and failure on clinical placement: A critical narrative review. International Journal of Language \& Communication Disorders, 53 (2), 218-227. https://doi.org/10.1111/1460-6984.12356

Deaville, J., \& Grant, A. (2011). Overcoming the pull factor of convenient urban living - Perceptions of rural general practice placements. Medical Teacher, 33(4), e211-e217. https://doi.org/10.3109/0142159X.2011.557409

Hair, J. F., Anderson, R. E., Tatham, R. L., \& Black, W. C. (1998). Multivariate Data Analysis (5th international edn.). Prentice Hall.

Health Workforce Australia. (2011). Rural and remote health workforce innovation and reform strategy: Draft Background Paper. Prepared for Health Workforce Australia by Siggins Miller. Retrieved November, 2019 from https://www.hwa.gov.au/sites/uploads/hwa-rural-and-remoteconsultation-draft-background-paper-20110829c.pdf

Hills, C., Quigley, D., Bennett, A., Haughey, F., \& McMahon, S. (2019). Core indicators of quality in practice education placement in allied health and social care professions: A scoping review protocol. JBI Database of Systematic Reviews and Implementation Reports, 17(6), 1060-1070. https://doi.org/10.11124/JBISRIR-2017-004031

Isaac, V., Pit, S. W., \& McLachlan, C. S. (2018). Self-efficacy reduces the impact of social isolation on medical student's rural career intent. BMC Medical Education, 18(1), 42. https://doi.org/10.1186/s12909-018-1142-1

Isaac, V., Walters, L., \& McLachlan, C. S. (2015). Association between self-efficacy, career interest and rural career intent in Australian medical students with rural clinical school experience. $B M J$ Open, 5(12), e009574. https://doi.org/10.1136/bmjopen-2015-009574

King, K., Purcell, R., Quinn, S., Schoo, A., \& Walters, L. (2016). Supports for medical students during rural clinical placements: Factors associated with intention to practise in rural locations. Rural and Remote Health, 16(2), Article 3791. https://www.rrh.org.au/journal/article/3791

Kline, R.B. (2015). Principles and practice of structural equation modeling (4th ed.). Guilford Press.

Longman, J. M., Barraclough, F. L., \& Swain, L. S. (2020). The benefits and challenges of a rural community-based work-ready program for allied health students. Rural and Remote Health, 20(3), Article 5706. d https://doi.org/10.22605/RRH5706

McAllister L. (2016). Quantifying quality clinical placements: Piloting measures of student clinical placement quality to improve student learning experiences. [Unpublished report]. The University of Sydney.

McAllister, L., Nagarajan, S., Scott, L., Smith, L., \& Thomson, K. (2018). Developing measures of placement quality in allied health, dentistry, medicine, and pharmacy. International Journal of Practice-based Learning in Health and Social Care, 6(2), 31-47. https://doi.org/10.18552/ijpblhsc.v6i2.493

McAllister, L., Paterson, M., Higgs, J., \& Bithell, C. (2010). Innovations in allied health fieldwork education: A critical appraisal. Practice, Education, Work and Society (Vol. 4). Sense. 
McCall, L., Wray, N., \& McKenna, L. (2009). Influence of clinical placement on undergraduate midwifery students' career intentions. Midwifery, 25(4), 403-410. https://doi.org/10.1016/j.midw.2007.07.008

Nolte, E., Fry, C.V., Winpenny, E., \& Brereton, L. (2011). Use of outcome metrics to measure quality in education and training of healthcare professionals: A scoping review of international experiences (RAND Europe working paper series). https://www.rand.org/pubs/working_papers/WR883.html

SAS Institute. (2020). Support/ Samples \& SAS Notes. Usage Note 33323: Producing Bartlett's test of sphericity. https://support.sas.com/kb/33/323.html

Siggins Miller Consultants. (2012). Promoting quality in clinical placements: Literature review and national stakeholder consultation. https://docplayer.net/10887025-Promoting-quality-in-clinicalplacements-literature-review-and-national-stakeholder-consultation-final-report.html

Smith, T., Cross, M., Waller, S., Chambers, H., Farthing, A., Barraclough, F., Pit, S. W., Sutton, K., Muyambi, K., King, S., \& Anderson, J. (2018). Ruralization of students' horizons: Insights into Australian health professional students' rural and remote placements. Journal of Multidisciplinary Healthcare, 11, 85-97. https://doi.org/10.2147/JMDH.S150623

Smith, T., Sutton, K., Pit, S., Muyambi, K., Terry, D., Farthing, A., Courteney, C., \& Cross, M. (2018). Health professional students' rural placement satisfaction and rural practice intentions: A national cross-sectional survey. Australian Journal of Rural Health, 26(1), 26-32. https://doi.org/10.1111/ajr.12375

Statistics How To. (2020). Statistics for the rest of us! Kaiser-Meyer-Olkin (KMO) Test for Sampling Adequacy. https://www.statisticshowto.datasciencecentral.com/kaiser-meyer-olkin/

van der Zwet, J., Zwietering, P. J., Teunissen, P. W., van der Vleuten, C. P. M., \& Scherpbier, A. J. J. A. (2011). Workplace learning from a socio-cultural perspective: Creating developmental space during the general practice clerkship. Advances in Health Sciences Education, 16(3), 359-373. https://doi.org/10.1007/s10459-010-9268-X

Wakerman, J., \& Humphreys, J. S. (2013). Sustainable workforce and sustainable health systems for rural and remote Australia. Medical Journal of Australia, 199 (5), S14-S17. https://doi.org/10.5694/mja11.11639

Wakerman, J., \& Humphreys, J. S. (2019). "Better health in the bush": Why we urgently need a national rural and remote health strategy. Medical Journal of Australia, 210(5), 202-203. https://doi.org/10.5694/mja2.50041

Walters, L., Seal, A., McGirr, J., Stewart, R., DeWitt, D., \& Playford, D. (2016). Effect of medical student preference on rural clinical school experience and rural career intentions. Rural and Remote Health, 16(4), 3698.

Winterton, J., \& Turner, J. J. (2019). Preparing graduates for work readiness: An overview and agenda. Education and Training, 61(5), 536-551. https://doi.org/10.1108/ET-03-2019-0044 


\section{APPENDIX A}

Table A.1: Item-to-Item correlations and Item-to-Total correlations for the 7 items of the Placement Quality Survey $(n=160)$.

\begin{tabular}{|c|c|c|c|c|c|c|c|}
\hline & Fit & Supervision & Learning & Communication & Culture & $\begin{array}{l}\text { Best } \\
\text { Practice }\end{array}$ & $\begin{array}{l}\text { Item- } \\
\text { Total } \\
\text { PQS } \\
(7- \\
\text { item) }\end{array}$ \\
\hline Quality & 0.592 & 0.466 & 0.599 & 0.537 & 0.477 & 0.420 & 0.640 \\
\hline Fit & & 0.777 & 0.629 & 0.505 & 0.532 & 0.557 & 0.763 \\
\hline Supervision & & & 0.602 & 0.419 & 0.469 & 0.563 & 0.683 \\
\hline $\begin{array}{l}\text { Learning } \\
\text { Environment }\end{array}$ & & & & 0.628 & 0.657 & 0.562 & 0.784 \\
\hline Communication & & & & & 0.629 & 0.492 & 0.685 \\
\hline Culture & & & & & & 0.531 & 0.705 \\
\hline Best Practice & & & & & & & 0.646 \\
\hline
\end{tabular}

Table A.2: Item-to-Item correlations and Item-to-Total correlations additional two items with the original 7 items of the Placement Quality Survey $(n=160)$

\begin{tabular}{|l|l|l|}
\hline & Autonomous & Work ready \\
\hline Quality & 0.531 & 0.557 \\
\hline Fit & 0.457 & 0.565 \\
\hline Supervision & 0.402 & 0.502 \\
\hline $\begin{array}{l}\text { Learning } \\
\text { Environment }\end{array}$ & 0.509 & 0.584 \\
\hline Communication & 0.342 & 0.468 \\
\hline Culture & 0.354 & 0.464 \\
\hline Best Practice & 0.320 & 0.450 \\
\hline Autonomous & 1.000 & 0.638 \\
\hline Work Ready & 0.638 & 1.000 \\
\hline Item-to-Total & 0.562 & 0.686 \\
\hline
\end{tabular}

Table A.3a: Fit statistics for the three Single construct Confirmatory Factor Analysis models - 9 items

\begin{tabular}{|l|l|l|l|}
\hline & Model 1 & Model 2 & Model 3 \\
\hline Measures of fit & & & \\
\hline Model chi-square & 75.8 & 59.7 & 39.6 \\
\hline Model chi-square $d f$ & 27 & 26 & 25 \\
\hline Prob Model chi-square & $<0.001$ & 0.0002 & 0.032 \\
\hline Model chi-square/df ratio & 2.81 & 2.30 & 1.58 \\
\hline$R M R$ & 0.267 & 0.174 & 0.095 \\
\hline SRMR & 0.205 & 0.133 & 0.065 \\
\hline Goodness of Fit Index & 0.878 & 0.904 & 0.936 \\
\hline Adjust GFI & 0.796 & 0.833 & 0.885 \\
\hline$R M S E A$ & 0.107 & 0.090 & 0.061 \\
\hline$R M S E A$ 90\%CI & $0.079-$ & $0.060-0.121$ & $0.018-0.095$ \\
& 0.135 & & \\
\hline$A I C$ & 111.8 & 97.7 & 79.6 \\
\hline Bentler CFI & 0.680 & 0.779 & 0.904 \\
\hline
\end{tabular}

Key: $d f$ - degrees of freedom; $R M R$ - root mean square residual; $S R M R$ - Standardized Root Mean Square Residual; GFI - Goodness of fit; RMSEA - Root Mean Square Error of Approximation; AIC Akaike information criterion 
Table A.3b: Results of Single construct Confirmatory Factor Analysis modelling - Model 3 parameters for the 9-item CFA with two additional covariance terms

\begin{tabular}{|c|c|c|c|c|}
\hline Parameter & & Unstandardised & $S E$ & Standardised \\
\hline \multicolumn{5}{|l|}{ Loadings from F1 } \\
\hline Quality & $\lambda 1$ & 0.812 & 0.065 & 0.773 \\
\hline Fit & $\lambda 2$ & 1.000 & & 0.792 \\
\hline Supervision & $\lambda 3$ & 0.911 & 0.054 & 0.709 \\
\hline Learning Environment & $\lambda 4$ & 1.031 & 0.069 & 0.881 \\
\hline Communication & $\lambda 5$ & 1.008 & 0.088 & 0.800 \\
\hline Organisational Culture & $\lambda 6$ & 1.065 & 0.083 & 0.800 \\
\hline Best Practice & $\lambda 7$ & 0.843 & 0.069 & 0.705 \\
\hline Autonomous & $\lambda 8$ & 0.652 & 0.084 & 0.636 \\
\hline Work Ready & $\lambda 9$ & 0.755 & 0.074 & 0.704 \\
\hline \multicolumn{5}{|l|}{ Variances/Covariances } \\
\hline Latent variable F1 & Phil & 0.921 & 0.126 & \\
\hline Quality & Var 1 & 0.408 & 0.049 & \\
\hline Fit & Var 2 & 0.547 & 0.066 & \\
\hline Supervision & Var 3 & 0.755 & 0.090 & \\
\hline Learning Environment & Var 4 & 0.282 & 0.044 & \\
\hline Communication & Var 5 & 0.528 & 0.063 & \\
\hline Organisational Culture & Var 6 & 0.588 & 0.091 & \\
\hline Best Practice & Var 7 & 0.660 & 0.093 & \\
\hline Autonomous & Var 8 & 0.575 & 0.067 & \\
\hline Work Ready & Var 9 & 0.534 & 0.068 & \\
\hline Covar Fit $\leftrightarrow$ Supervision & Cov 23 & 0.303 & 0.069 & \\
\hline $\begin{array}{l}\text { Covar Autonomous } \leftrightarrow \text { Work } \\
\text { Ready }\end{array}$ & Cov 89 & 0.228 & 0.050 & \\
\hline
\end{tabular}

